\section{Prevalence of female urinary incontinence in the state of Roraima, Brazil}

\author{
Mário Maciel De Lima Junior, ${ }^{1}$ \\ Elizângela Castelo Branco²
}

${ }^{1}$ Department of Uro-Gynecology of Reference Center of Women's Health Hospital, Roraima; ${ }^{2}$ Cathedral College, Roraima, Brazil

\begin{abstract}
Urinary incontinence (UI) is a significant health problem leading to physical, psychological and social discomfort, especially in elderly women. A study of prevalence and classification of UI in the Roraima state was taken up to aid in formulation of healthcare policy and improvement of patient referral facilities. A retrospective study of 765 female patients who have undergone urodynamic examination between November 2013 and December 2014 has been conducted. Subjects were classified in to diagnostic classes: normal, stress incontinence, mixed incontinence, sensitive emergency, overactive bladder, and others. The overall prevalence of UI was $58.4 \%$. The highest prevalence was observed in the menopausal age group (4549 years). Among the etiologies of UI, stress incontinence ranked highest at $30.9 \%$, followed by overactive bladder at $6.9 \%$. In the $25-55$ years age group, stress incontinence was predominant (50-63\%), while overactive bladder became significant (14-44\%) in later years. The prevalence of UI in women in the state of Roraima, was high, in line with its prevalence in Brazil, as well as other western countries.
\end{abstract}

\section{Introduction}

Urinary incontinence (UI) has been defined by the International Continence Society (ICS) in 2002, as a complaint of involuntary leakage of urine. ${ }^{1}$ Commonly experienced worldwide, especially in elderly women, UI is the cause of physical discomfort and affects the individual socially and psychologically. According to the National Institute of Aging, UI can be caused by urinary tract and vaginal infection or irritation, and constipation. Longterm UI is due to weak bladder muscles, overactive bladder, or damage to the nerves that control the bladder from diseases such as, multiple sclerosis and Parkinson's dis- ease. ${ }^{2,3}$ Prevalence of UI varies depending on the definition of UI used, the methodology used for the surveys, such as the questionnaire, and the study population. There have been many reviews and reports on the prevalence of UI in Europe and the USA. ${ }^{4}$ However, it is difficult or impossible to determine the cause of UI from these studies, due to considerable variation in the questions and responses. Therefore, the use of validated questionnaires and techniques of analytical epidemiology have been recommended, so that data on different types and etiologies of UI are acquired. ${ }^{5}$

Numerous studies have examined the prevalence of UI in the southern and southeastern region of Brazil. ${ }^{6-9}$ Only one study by Carey et al., have investigated the occurrence of UI in northeastern region of Brazil. ${ }^{10}$ Clearly, there are no studies on UI from the northern Amazon region of the country. In addition, there has not been any study of prevalence of UI in the State of Roraima, which belongs to this region north of Amazon. An assessment of the prevalence of female UI in the State would be useful in the development of public health policies and improvement of patient referral facilities in the State of Roraima, Brazil. In view of this, a systematic study has been conducted to evaluate the prevalence of female UI, and to understand the types of UI, such as stress, overactive or mixed UI, prevalent in the community.

Patient reported UI symptoms are subjective and less reliable for diagnosing UI. ${ }^{11,12}$ Rather, urodynamic investigations are considered better for measuring the lower urinary tract dysfunction. ${ }^{12}$ Although ICS has mentioned that urodynamic observations can have many other possible underlying causes rather than the disease itself, number of studies has shown a strong correlation between urodynamic results and stress UI. ${ }^{11,12}$ Moreover when UI patient are presented with a complex of symptoms, urodynamics becomes essential for objective diagnosis. ${ }^{11}$

Therefore, the objective of the present study is to evaluate UI based on urodynamic study reports as it tries to reproduce the patients' symptoms and is useful in deciding the treatment.

\section{Materials and Methods}

The present retrospective study of female UI is conducted at the Women's Health Reference Center in Boa Vista, State of Roraima, Brazil, with approval from the Institutional Health System Committee. The cases were analyzed from a single center (who treated female urinary incontinence
Correspondence: Mário Maciel De Lima Junior, Rua Levindo Inácio de Oliveira, 1547, Paraviana, CEP 69307 - 272, Boa Vista - RR, Brazil.

Tel.: 55.95.3623.0174 - Fax: 55.95.9123.0778. E-mail:mmljr@uol.com.br

Key words: Epidemiology; overactive bladder; prevalence; stress incontinence; urinary incontinence.

Acknowledgments: we acknowledge the assistance of Magna Bezerra Feitosa in collection of data.

Contributions: MMDL Jr, conception and design the study, drafting the manuscript, analysis and interpretation the data, revising the manuscript critically, approval of the final version; $\mathrm{ECB}$, acquisition of data, revising the manuscript critically, approval of the final version.

Conflict of interest: the authors declare no potential conflict of interest.

Received for publication: 28 June 2016

Revision received: 8 May 2017.

Accepted for publication: 1 June 2017.

This work is licensed under a Creative Commons Attribution NonCommercial 4.0 License (CC BY-NC 4.0).

(C) Copyright M.M. De Lima Junior and E. Castelo Branco, 2017

Licensee PAGEPress, Italy

Urogynaecologia 2017; 30:183

doi:10.4081/uij.2017.183

problems) in Roraima, Brazil. The study was based on examination of records of 765 female patients who had appointments for urodynamic study between November 2013 and December 2014. All patients were referred to this only center of voiding dysfunctions in the state of Roraima (School hospital). All examinations were performed by the same urologist. As per protocol, patients had voiding diary and negative urine test for the procedure. The inclusion criteria for the study were that patient should not be institutionalized, and should have undergone urodynamic study to investigate voiding dysfunction at the hospital. With regard to urodynamic data, detrusor over activity was defined as clinical symptoms, voiding diary and contractions of the detrusor greater than $15 \mathrm{~cm} \mathrm{H}_{2} \mathrm{O}$ at the urodynamic study. Sensitive emergency was defined as clinical symptoms, voiding diary and absence of detrusor's contraction and low vesical capacity (less than $300 \mathrm{ml}$ ). Patients were excluded if they had either anterior or posterior pelvic organ prolapse and did not undergo urodynamic examina- 
tion. Only the quantitative information about the appointments and the diagnosis made by urodynamic study were used for the study as it is more objective and reliable. The prevalence of self-reported urinary incontinence appears to be less reliable, as mentioned in previous studies. Each patient was classified in to one of following eight classes, based on their urodynamic assessment: i) neurogenic bladder; ii) normal study; iii) overactive bladder; iv) incoordination voiding; v) stress incontinence; vi) mixed incontinence; vii) infravesical obstruction; and viii) sensitive emergency.

\section{Statistical analysis}

All descriptive statistics and other tests of statistical significance between groups were performed using SAS software suite (SAS Institute Inc., NC USA). Chi-square test was used for the comparison of multiple diagnostic classes at $95 \%$ confidence interval $(\mathrm{CI})$. $\mathrm{P}$ value $<0.05$ was considered statistically significant.

\section{Results}

Three patients were excluded from the study, as they did not have age data. The subjects of the study $(\mathrm{N}=762)$ belonged to the age range 5-85 years. None of the patients had urinary tract infection, prolapse, and use of medications for any voiding dysfunction problems.

Nine percent of the sample had previous surgery for urinary incontinence (BURCH). Out of the study population, 445 (58.4\%) were diagnosed with UI. The distribution of prevalence of UI among different age groups in the population of women in the State of Roraima is shown in Figure 1, and the prevalence is compared to the women population in Table 1. The prevalence is above $6 \%$ for the age group 35-54 years, and is below $4 \%$ for all the other age groups. Prevalence of UI is highest for the age group 45-49 (about one in ten women), followed by age groups 50-54 years $(8.79 \%)$. Above 55 years and up to 75 years, the prevalence of $3-4 \%$ is maintained, that is, only 3-4 out of every 100 women may be affected by UI, but declines further thereafter in very senior population ( $>75 \mathrm{y}$ ). On the other hand, prevalence of UI is very small in the early ages of up to 30 years. A steady increase in the prevalence of UI is observed, from $3.94 \%$ in $30-34$ age groups, to $6.82 \%$ for $35-39$, to $8.01 \%$ for the $40-44$ years group.

Subjects were assigned to different diagnostic classes after examination of their urodyanamic study reports, as depicted in Figure 2. Out of the 762 subjects, 317 $(41.6 \%)$ were found to be normal based on their reports and the remaining were diagnosed with UI due to various etiologies. A majority of the UI patients, that is, 236 of them had stress incontinence, while 84 (one out of ten women) of them had a sensitive emergency. Overactive bladder symptoms were found in 53 (about seven in 100 women) and in coordination voiding accounted for 41 (about six in 100 women) of the subjects. Other etiologies were prevalent to the extent of $2 \%$ or less with neurogenic bladder in 19 (about two in 100 women), mixed incontinence in nine (about one in 100 women) and infra-vesicular

obstruction in three (about four in 1000 women) of the patients.

When the population is classified as relatively younger (18-44 y), middle aged (45$59 \mathrm{y})$ and senior $(>60 \mathrm{y})$ women, the first two sub-groups had similar prevalence of all the types of etiologies. However, in the case of seniors, there was a marked decrease in stress incontinence (about $11 \%)$ and sensitive emergencies $(-15 \%)$, but a significant increase in overactive bladder $(+13.8 \%)$ and other etiologies $(+9.4 \%)$, as shown in Table 2. A chi-squared test for comparison of multiple groups was not reliable as the minimum expected value obtained was $<5 .{ }^{13}$

Figure 3 displays the prevalence of each

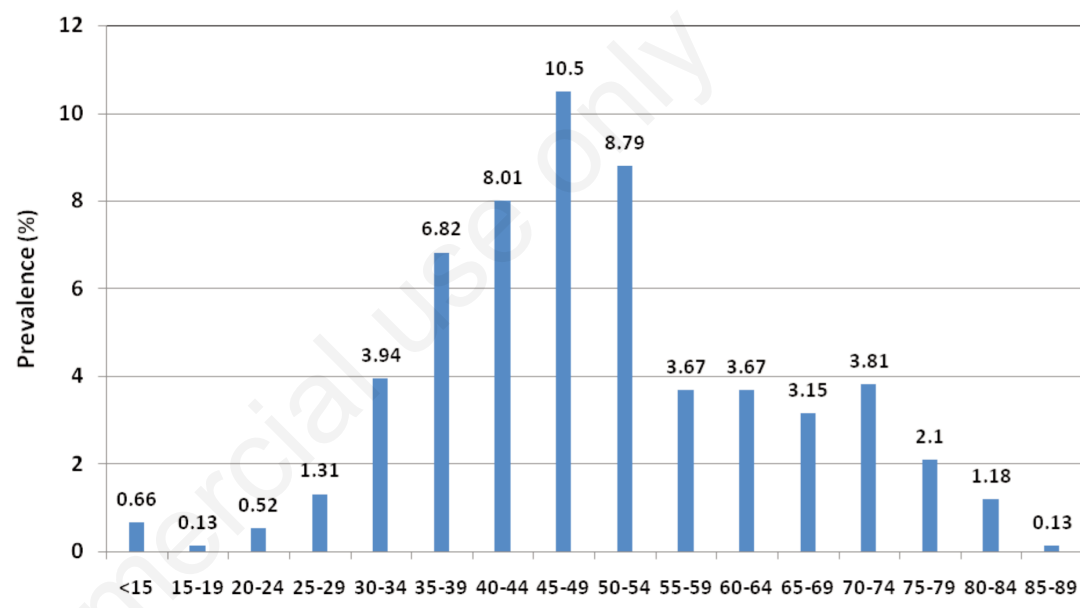

Age groups (years)

Figure 1. Prevalence of urinary incontinence in women from the State of Roraima, Brazil.

Table 1. Prevalence of urinary incontinence in comparison with women population of Boa Vista, Brazil.

\begin{tabular}{lcc} 
Age group (y) & Population (\%) & Prevalence of U/*, n (\%) \\
$<15$ & - & $5(0.66)$ \\
$15-19$ & 5.22 & $1(0.13)$ \\
\hline $20-24$ & 4.81 & $4(0.52)$ \\
$25-29$ & 4.46 & $10(1.31)$ \\
\hline $30-34$ & 4.05 & $30(3.94)$ \\
$35-39$ & 3.28 & $52(6.82)$ \\
\hline $40-44$ & 2.73 & $61(8.01)$ \\
$45-49$ & 2.26 & $80(10.50)$ \\
\hline $50-54$ & 1.88 & $67(8.79)$ \\
$55-59$ & 1.42 & $28(3.67)$ \\
\hline $60-64$ & 0.97 & $28(3.67)$ \\
$65-69$ & 0.60 & $24(3.15)$ \\
\hline $70-74$ & 0.38 & $29(3.81)$ \\
$75-79$ & 0.24 & $16(2.10)$ \\
\hline $80-84$ & 0.14 & $9(1.18)$ \\
$85-89$ & 0.07 & $1(0.13)$
\end{tabular}

*Urinary incontinence (UI) relative to the total number of subjects $(\mathrm{N}=762)$. 
of the etiologies for UI in different age groups of the subject population. The most common etiology of stress incontinence is observed in the age range 30-74 years, where one out of every two UI patients has stress incontinence, except for a sudden decline to $25 \%$ (one in four women) for the age group 55-59 years. Sensitive emergency is the next most prevalent being seen in one in five women of age up to 60 years and declines thereafter. However, it is the overactive bladder and other types of etiologies (that is, neurogenic bladder, in coordination voiding and infravesicle obstruction) that are prevalent in about one in three subjects aged above 65 years. Mixed incontinence is prevalent to a small extent (5-10\%) in patients aged 40 and above.

\section{Discussion and Conclusions}

Roraima state of Brazil has a population of approximately 505,000 with $49 \%$ female population. ${ }^{13,14}$ In the absence of epidemiological data on UI in this region, this study was taken up in order to estimate the prevalence and type of UI present in the population, and to plan for the establishment of clinical support measures, medication, physical therapy and surgery in these patients, leading to reduced morbidity, improvement in their quality of life.

Similar to our study, many other studies have also reported a high prevalence of UI in females in different parts of the world. $\mathrm{Wu}$ et al. demonstrated an overall prevalence of UI as high as our study, which included females of different races, i.e. Whites, African American, Asian as well as Latina, presented with non cancerous gynecological problems and among them Latin women had the highest incidences of UI. ${ }^{15}$ In elderly Brazilian women, a high prevalence of UI was seen which was positively associated with white race, physical inactivity, stroke, mobility impairment, and cognitive decline. ${ }^{9}$ In the studies mentioned above, the mean age of the participants was 44.1 years, 50.6 years and 81.5 years, respectively. ${ }^{8,15,16}$ Similarly, another study

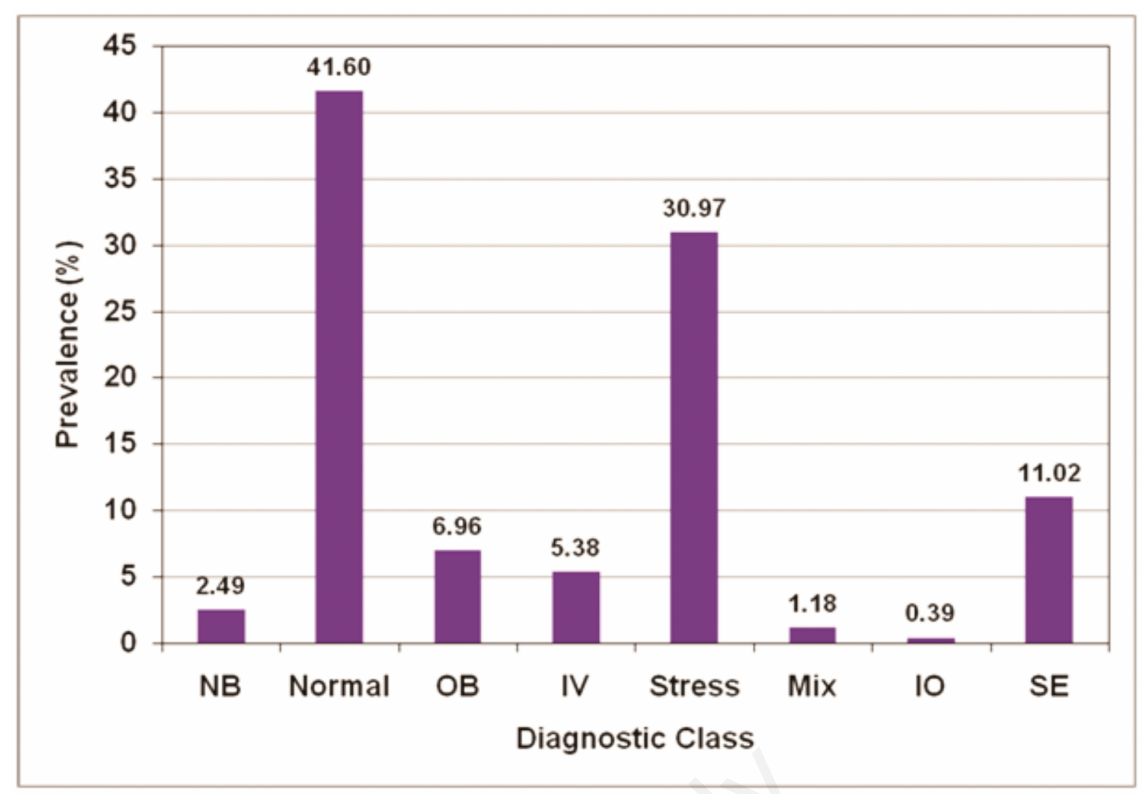

Figure 2. Prevalence of according to the type of urinary incontinence.

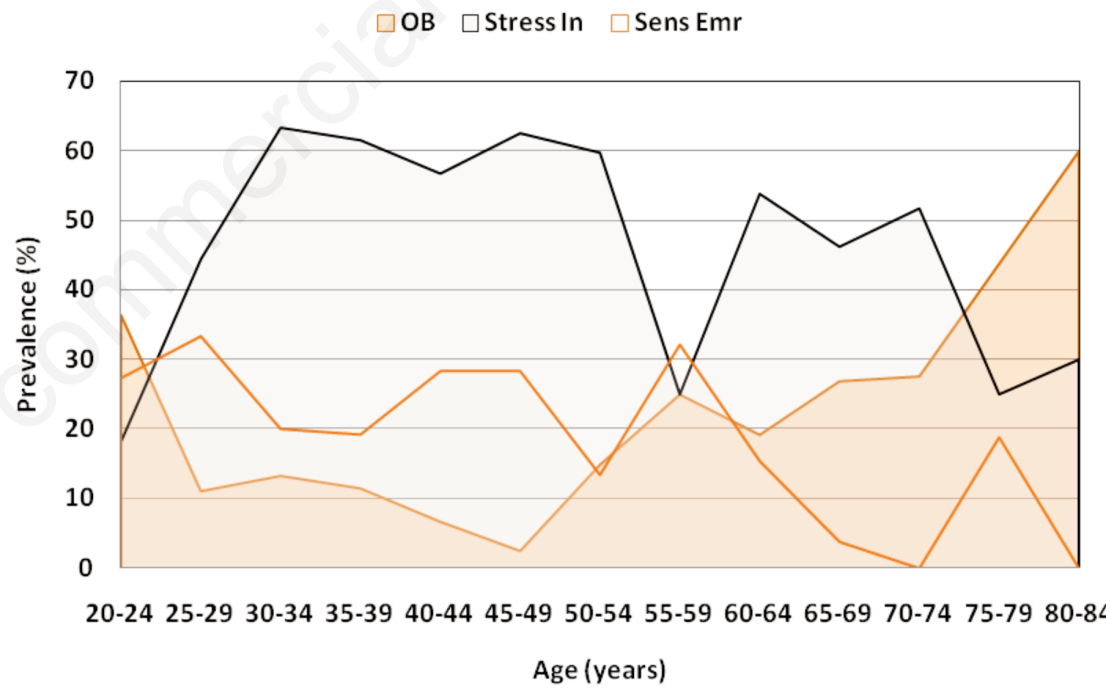

Figure 3. Distribution of different types of urinary incontinence according to the age group of subjects.

Table 2. The relative distribution (\%) of the type of incontinence by different age bands.

\begin{tabular}{lcccccccc} 
Age $(\mathrm{y})$ & Overactive bladder & Stress incontinence & Mixed incontinence & Sensitive emergency & Others & Tot & Prevalence $\%$ \\
$18-44$ & $15(9.2 \%)$ & $91(55.8 \%)$ & $0(0 \%)$ & $39(23.9 \%)$ & $18(11.1 \%)$ & 162 & $36.55(\mathrm{Cl}: 32.0-40.8)$ \\
$45-59$ & $14(8 \%)$ & $97(55.4 \%)$ & $4(2.2 \%)$ & $37(21.1 \%)$ & $23(13.1 \%)$ & 175 & $39.24(\mathrm{Cl}: 34.9-43.7)$ \\
\hline$>60$ & $24(22.2 \%)$ & $48(44.4 \%)$ & $5(4.6 \%)$ & $8(7.4 \%)$ & $23(21.3 \%)$ & 108 & $24.22(\mathrm{Cl}: 20.3-28.2)$ \\
Total & 53 & 236 & 9 & 84 & 18.8 & 14.3 & 445 & 100.00 \\
\hline$\% *$ & 11.9 & 53.0 & 2.02 & & & - \\
\hline
\end{tabular}

*Relative to the total number of subjects diagnosed with urinary inconsistence $(\mathrm{n}=445)$. 
from northeastern region of Brazil included female climacteric patients with mean age higher than ours. ${ }^{9}$ From all these studies, it can be inferred that gynecological problems and parity seems to be the most important causes of UI in pre-menopausal females. Contrary, to the above studies, our study had relatively younger population. Borges et al. has shown a high rate of fertility in very young adolescent women in Brazil, which was highest in northern Brazil and lowest in southern Brazil. ${ }^{17}$ Giving birth at an adolescent age is associated with many gynecological problems, such as puerperal endometritis, episiotomy, postpartum hemorrhage, operative vaginal delivery, etc. Moreover, Roraima has predominantly younger population while older women pertaining to Brazilian Amazon culture, resist visiting hospitals for check up. These two reasons might have contributed for high prevalence of UI in younger population in our study.

A large number of previous studies have used various questionnaires to obtain information about UI. ${ }^{6-8}$ However, there exists significant subjectivity in conveying the symptoms and is difficult to ascertain the cause of incontinence. Urodynamic testing on the other hand is a useful technique for objective diagnosis of the UI. ${ }^{11}$ This investigation, though expensive, is required in conjuction with clinical examination for accurate diagnosis of stress UI. ${ }^{11,18,19}$ Further, irrespective of UI types, where clinical examination or self-reported questionnaire are unsuccessful in diagnosing the disease, and when neurological co-morbid conditions exists, urodynamic investigation becomes necessary for differentiating the UI types for initiating proper treatment. ${ }^{10}$

Prevalence of different types of UI varies greatly throughout the world. Stress UI is the predominant UI type observed in our population in all the age ranges. Accordingly, Hunskaar et al. have reported the mean prevalence of stress incontinence to be $48 \%$ (range $29-75 \%$ ) for women of age 18-79 years, based a review of several previous studies. ${ }^{20,21}$ Nonetheless, stress incontinence is reduced age $>60 \mathrm{y}$ but overactive bladder and sensitive emergency become the predominant UI types. Such a trend of reduced prevalence past the peak menopausal age has also been reported by Sandvik et al. ${ }^{14}$ In a previous questionnaire based study of patients aged 15-55 years in Brazil, overactive bladder symptoms were equally prevalent among all the age groups. However, in the present study, its prevalence remains at approximately one in ten women of age up to 45 years, but shows a steady rise to two in ten in the age group 55$59 \mathrm{y}$, and then to more than four out of ten women of 75-79 y age group. In another study of young women in Brazil, women of age group 35-45 years showed significantly high scores for symptoms of overactive bladder, but this is in contrast to our study. ${ }^{20}$ On the other hand, a comparable trend is seen in a study of men and women aged 2091 y from Vienna, Austria. ${ }^{21}$ This study concluded that overactive bladder symptoms with incontinence increased substantially after the age of 40. A similar increasing trend of overactive bladder symptoms with age, especially after $44 \mathrm{y}$, has been seen in American women. ${ }^{22}$ The increased prevalence of overactive bladder with age has also been reported in survey-based studies in the European countries, ${ }^{23}$ Korea, ${ }^{24}$ Japan, ${ }^{25}$ and the EPICC study. ${ }^{26}$ Of particular interest to the present study, Davila et al. have reported a high prevalence of overactive bladder in the age group 65-69 years, in their study of men and women of 18-75 years in Venezuela. ${ }^{27}$ Mixed incontinence accounted for a low prevalence of one in 100 of the study population. There were only nine cases, out of which seven were in the age group 45-65 years. However, the prevalence of mixed incontinence reported in other studies is much higher. ${ }^{4}$ Among the other types of incontinence, only incoordination voiding has relatively higher prevalence at $5.38 \%$. Interestingly, sensitive emergencies are as high as $30 \%$ (about one in three women) for the 55-59 years of age group, while there is a sharp decline in stress incontinence. There is a sharp decline in emergencies beyond 60 years up to $>75$ years.

The discrepancies in the prevalence rate of UI types in different age groups is attributed mainly to the method used for diagnosing UI. Most of the studies use self-reported questionnaire for evaluating UI whose response is subjective and this can cause wide variations in the prevalence rate. Despite controversies, vaginal delivery is the most commonly associated reason for UI in females of all ages. ${ }^{28-30}$ Irrespective of the type of UI and age, female gynecological and birth related problems like parity, menopause, recurrent UTI, hysterectomy, number of abortions, fetal weight; body mass index (BMI), and comorbid condition, such as diabetes and chronic pulmonary disease, are the risk factors commonly associated with UI. ${ }^{30}$ Therefore, addressing these issues at proper time might reduce the severity or incidence of UI. We speculate that reducing high birth rate in very young women of our region by providing proper education might be a means to address this issue.

The present study provides valuable data on the prevalence of UI in the state of
Roraima, Brazil, thereby facilitates development of a healthcare policy to deliver clinical support measures, such as medication, physical therapy and surgery, to reduce morbidity and improve the quality of life for these patients.

\section{References}

1. Abrams P, Cardozo L, Fall M, et al. The standardisation of terminology of lower urinary tract function: report from the standardisation sub-committee of the International Continence Society. Neurourol Urodyn 2002;21:167-78.

2. Brito LG, Brito LM, Chein MB, Malheiros ES, Duarte TB, PintoNetoAM. Stress urinary incontinence in climacteric women in a Northeastern Brazilian municipality: a household survey. Int Urogynecol J. 2012 May;23: 639-45.

3. National Institute of Aging (NIH). Urinary incontinence. 2013. Available from: https://www.nia.nih. gov/sites/default/files/UrinaryPartsAPfi nalproof 0.pdf

4. Hunskaar S, Lose G, Sykes D, Voss S. The prevalence of urinary incontinence in women in four European countries. BJU Intl 2004;93:324-30.

5. Abrams P, Cardozo L, Khoury S, Wein A. Incontinence. 2nd ed. 2nd International Consultation on Incontinence, Plymouth, UK: Health Publication Ltd; 2002.

6. Katz MH. Study design and statistical analysis: A practical guide for clinicians. UK: Cambridge University Press; 2006.

7. Amaro JL, Macharelli CA, Yamamoto $\mathrm{H}$, et al. Prevalence and risk factors for urinary and fecal incontinence in brazilian women. INT BRAZ J UROL 2009;35:592-8.

8. Reigota, RB, Pedro AO, de Souza Santos Machado V, et al. Prevalence of urinary incontinence and its association with multimorbidity in women aged 50 years or older: A population-based study. Neurourol Urodynam 2014; 35:62-8.

9. Jerez-Roig J, Santos MM, Souza Dyego LB, et al. Prevalence of urinary incontinence and associated factors in nursing home residents. Neurourol Urodynam 2016;35:102-7.

10. Carey MP, Dwyer PL, Glenning PP. The sign of stress incontinence--should we believe what we see? Aust N Z J Obstet Gynaecol 1997;37:436-9.

11. Rosier PF. The evidence for urodynamic investigation of patients with symp- 
toms of urinary incontinence F1000. Prime Rep 2014;5:8.

12. Lemack GE, Zimmern PE. Identifying patients who require urodynamic testing before surgery for stress incontinence based on questionnaire information and surgical history. Urology 2000;55:50611.

13. Instituto Brasileiro de Geografia e Estatística (IBGE). Projeções e estimativas da população do Brasil e das Unidades da Federação; 2013. Available from: http://www.ibge.gov.br/apps/populacao/projecao/

14. Sandvik H. Female urinary incontinence: studies of epidemiology and management in general practice [thesis]. Bergen: Department of Public Health and Primary Health Care, University of Bergen; 1995.

15. Wu MJ, Stinnett S, Jackson RA, et al. Prevalence and incidence of urinary incontinence in a diverse population of women with noncancerous gynecologic conditions. Female Pelvic Med Reconstr Surg 2010;16:284-9.

16. Ahmed HA, Osman VA, Al-Alaf SK, Al-Tawil NJ. Prevalence of urinary incontinence and probable risk factors in a sample of Kurdish women. Sultan Qaboos Univ Med J 2013;13:269-74.

17. Borges ALV, Chofakian Borges do Nascimento C, Simões Duarte L, Novaes Gomes M. Fertility rates among very young adolescent women: temporal and spatial trends in Brazil. BMC Pregnancy Childbirth 2016;16:57.

18. Martin JL, Williams KS, Abrams KR, et al. Systematic review and evaluation of methods of assessing urinary incontinence. Health Technol Assess 2006; 10:1-132.

19. Weber AM, Walters MD. Cost-effectiveness of urodynamic testing before surgery for women with pelvic organ prolapsed and stress urinary incontinence. Am J Obstet Gynecol 2000;183:1338-46.

20. Teloken C, Caraver F, Weber FA, et al. Overactive bladder: prevalence and implications in Brazil. Eur Urol 2006;49:1087-92.

21. Temml C, Heidler S, Ponholzer A, Madersbacher S. Prevalence of the overactive bladder syndrome by applying the International Continence Society definition. Eur Urol 2005;48:622-27.

22. Stewart WF, Van Rooyen JB, Cundiff $\mathrm{GW}$, et al. Prevalence and burden of overactive bladder in the United States. World J Urol 2003;20:327-36.

23. Milsom I, Abrams P, Cardozo L, et al. How widespread are the symptoms of an overactive bladder and how are they managed? A population-based prevalence study. BJU Int 2001;87:760-6.

24. Lee YS, Lee KS, Jung JH, et al. Prevalence of overactive bladder, uri- nary incontinence, and lower urinary tract symptoms: results of Korean EPIC study. World J Urol 2011;29:185-90.

25. Homma Y, Yamaguchi O, Hayashi K. NBSE: An epidemiological survey of overactive bladder symptoms in Japan. BJU Int 2005;96:1314-8.

26. Martinez-Agullo E, Ruiz-Cerda JL, Arlandis S, et al. Analysis of overactive bladder and urinary incontinence in working women aged between 25 and 64 years EPICC study. Actas Urol Esp 2010;34:618-24.

27. Dávila HA, López V, Nieves L, et al. Demographic distribution and prevalence of overactive bladder in Venezuela. Actas Urol Esp 2010;34: 176-80.

28. Hampel C, Artibani W, Espuña Pons M, Haab F, Jackson S, Romero J, et al. Understanding the burden of stress urinary incontinence in Europe: a qualitative review of the literature. Eur Urol 2004;46:15-27.

29. Melville JL, Katon W, Delaney K, Newton K. Urinary incontinence in US women: a population-based study. Arch Intern Med 2005;165:537-42.

30. Seshan V, Al Khasawneh E, Hamed Al Hashmi I. Risk factors of urinary incontinence in women: a literature review. Int J Urol Nurs 2016;10:118-26. 